\title{
Política social, governança e capacidade: reformas e restrições do setor público*
}

James Warner Björk man

“...O início da sabedoria na elaboração de estratégias de desenvolvimento consiste em abandonar como diretrizes de ação as ideologias dogmáticas que confundiram a política e a gestão do desenvolvimento nos últimos anos. A realidade fundamental que deve dar forma à gestão do desenvolvimento socioeconômico é a interdependência essencial entre governos, mercados e a ação voluntária. Suas relações não constituem um jogo de soma zero, mas, sim, complementaridades que precisam evoluir dentro de padrões específicos para cada setor da atividade socioeconômica"

Milton J Esman (1991, p. 12-13)

\section{Introdução}

Entre os vários relatórios de avaliação de programas sociais no Brasil, Barros e outros (2005) confirmam que as desigualdades sociais constituem um grande problema na América Latina. O Relatório de desenvolvimento humano (PNUD, 2003) destaca que, dos 12 países com pontuação mais alta em termos de concentração de renda, seis estão na América Latina e os outros seis, na África. Entre a meia dúzia de países latino-americanos da lista, o Brasil tem o coeficiente GINI mais alto $(60,7)$. Uma estratégia padrão para reduzir a desigualdade tem sido a de implementar programas sociais direcionados para a população mais pobre. O utra estratégia bem estabelecida no Brasil é a adoção de programas de cobertura 
universal, tal como o sistema unificado de atenção à saúde - o Sistema Único de Saúde - criado pela Constituição de 1988 (VIANa et al., 1997, p. 331). Tais medidas têm muitos méritos, a despeito de seus desgastes crônicos e desapontamentos.

Políticas públicas são um campo complexo do conhecimento, que exige abordagens multidisciplinares e até mesmo interdisciplinares. D écadas de experiência na Ásia e na África sugerem que a reforma nem sempre é algo positivo e, sem dúvida, alguns poderiam até dizer que "nenhuma boa ação fica sem punição". Tendo em vista que sistemas de saúde são problemáticos e tentativas de reforma são inevitáveis, este artigo pretende rever a lógica da Nova G estão Pública (NG P) no setor de saúde. Propõe-se a examinar mais detalhadamente as reformas aplicadas à prestação de serviços de saúde e sugere estratégias para a reforma do setor, levando em conta a capacidade.

\section{Antecedentes históricos das "abordagens"}

Como breve pano de fundo para as atuais ref ormas do setor público, as abordagens de capacitação para a política social evoluíram ao longo dos últimos 50 anos (Whyte, 2004). Os anos 1950 e 60 foram caracterizados pelo "desenvolvimento institucional", uma abordagem focada em organizações individuais, modeladas de acordo com as existentes nos países desenvolvidos, quando não transferidas diretamente deles. Durante essas décadas, muitas instituições do setor público foram criadas, incluindo empresas estatais com forte ênfase na prestação de serviços sociais pelo Estado. No final dos anos 60 e início dos 70, 0 foco inicial no desenvolvimento institucional atenuou-se para dar lugar à preocupação em fortalecer as instituições já existentes. A ênfase no "fortalecimento institucional" buscou fornecer ferramentas para a melhoria do desempenho, ao invés da promoção de mudanças em grande escala.

Os anos 60 e 70 também testemunharam o auge da "administração do desenvolvimento" - ou, para usar o jargão atual, a "gestão do desenvolvimento" -, que procurou alcançar gruposalvo negligenciados e, em especial, melhorar os sistemas de prestação de serviços para tanto. G rande ênfase foi conferida ao papel dos agentes do governo, particularmente os servidores públicos civis: o desenvolvimento foi cada vez mais focado em pessoas e não em instituições. Durante a década de 80 , a nomenclatura mudou novamente - desta vez, da "gestão/administração do desenvolvimento" para "gestão de recursos humanos". Os setores-chave a serem enfocados eram educação, saúde e população, surgindo o conceito de desenvolvimento centrado em pessoas.

Nesse período, o mote do "ajuste estrutural" traduziu-se em um composto de reformas das políticas públicas baseadas em requisitos ou "condicionalidades" de mudanças econômicas e sociais - , a serem realizadas por parte dos beneficiários dos recursos de financiadores. A capacitação passou a incluir esforços associativos e iniciativas do setor privado, em acréscimo à ação governamental. Mais atenção foi dada ao ambiente internacional e ao comportamento econômico nacional. Esse "neo-institucionalismo" também denominado "desenvolvimento de capacidade" - refletia a preocupação com a sustentabilidade da capacitação e, 
na década de 90, expressava, particularmente, um paradigma de "governança", que reunificou a administração pública e a participação política. Esse último período foi caracterizado também por uma reavaliação da cooperação técnica e de suas limitações, além do surgimento da "apropriação local" como um fator vital para o desenvolvimento.

Agora, nesta primeira década do século XXI, os Objetivos de D esenvolvimento do Milênio, endossados internacionalmente, tornaram-se a principal força motriz para a mudança baseada na gestão por resultados e em investimentos de longo prazo. A era do "reparo rápido", por sorte, acabou, e teve início o reconhecimento - e até mesmo a valorização do "avanço gradual". Dada a disseminação da tecnologia da informação, o foco está hoje nas redes de conhecimento, que proporcionam a aprendizagem contínua, bem como na adaptação sinérgica por meio da maior participação em capacitação.

\section{Três gerações de reformas do setor público}

Por várias décadas, as reformas do setor público basearam-se na premissa de que a melhoria da capacidade do governo de gerir resultaria em progresso socioeconômico. 0 Relatório do Desenvolvimento Mundial de 1997, elaborado pelo Banco Mundial (ver também BAnco Mundial, 1993), descreve uma primeira geração de reformas, na qual foram adotadas medidas para cortar os gastos do governo e revitalizar o setor privado. Elas incluíram cortes orçamentários, reformas fiscais, alguma privatização, liberação de preços e, mais visivelmente, esforços para reduzir o tamanho do setor público. Este último era descrito, quase invariavelmente, como "inchado" e que necessitava, portanto, de cirurgia, seguida por uma dieta severa.

Rapidamente ficou claro que a transformação do governo exigiria um longo período de tempo e que as economias resultantes da redução dos custos burocráticos seriam insuficientes para garantir até mesmo níveis básicos de prestação de serviços públicos. Uma segunda geração de reformas do setor

"Na prática, diversas políticas sociais têm sido elaboradas e implementadas como prionidades residuais de políticas econômicas e explicitamente rotuladas como programas 'compensatónios' para 'suavizar' o custo social de ajustes econômicos"

público procurou, então, melhorar a eficiência e a efetividade do governo. Enquanto a primeira geração de reformas enfatizava a redução do tamanho do Estado, a terceirização e a melhoria do controle sobre a orçamentação e os gastos públicos, as reformas da segunda geração promoveram a descentralização para os níveis sub-nacionais, a criação de agências semi-autônomas no governo 
central e reformas na gestão de recursos humanos (recrutamento, seleção, treinamento e desempenho).

Mais recentemente, a agenda da reforma foi novamente redirecionada para uma terceira geração de reformas, que busca melhorar os resultados sociais por meio da melhoria na prestação de serviços (Banco Mundial, 2001). Essa estratégia enfatiza abordagens setoriais, particularmente na saúde e na educação, a fim de produzir um programa coerente para a prestação de serviços, envolvendo organizações governamentais e nãogovernamentais.

Essas gerações de reformas, naturalmente, sobrepõem-se e não são estritamente seqüenciais, mas todas elas foram conduzidas por uma combinação de agências externas e internas. A ajuda multilateral e bilateral envolve condicionalidades que exigem (compromisso com) mudanças no comportamento do go verno, antes da transferência de recursos. Comissões nacionais de planejamento e ministérios das finanças exigem, por sua vez, que as agências adotem reformas que possam incluir uma combinação dessas gerações.

Apesar da retórica sobre 0 aumento do papel do setor privado e a redução do tamanho do Estado, a verdade é que 0 setor privado já participa extensamente na prestação da atenção à saúde nos países em desenvolvimento. De fato, na maioria de países, o setor privado é freqüentemente maior do que o setor público. No entanto, devido a barreiras ideológicas - ou ao que chamamos, às vezes, de "pensamento de manada" - , o setor privado não tem sido reconhecido e, de tal forma, não medido, ao menos em séries de dados públicas. Financiado principalmente pelos pagamentos feitos diretamente pelos pacientes, grande parte do setor privado na saúde é, tampouco, em larga medida, regulado. Conseqüentemente, em vez do "redimensionamento" do número de empregados - uma reforma geralmente que se aplica ao serviço público -, a maioria das reformas da NG P encontradas nos setores de saúde de países em desenvolvimento enfatizam a reestruturação interna do setor público, principalmente por meio da descentralização e da terceirização (outsourcing).

Note-se também que as reformas do setor de saúde têm um paralelo significativo nas reformas da administração pública. Na maioria dos casos, elas foram estimuladas pela recessão econômica e por sérios problemas fiscais no tesouro do Estado, e não por uma tendência ideológica a favor da reforma. A redução dos orçamentos públicos afetaram adversamente a prestação de serviços, mesmo em países que antes tinham sistemas que funcionavam razoavelmente bem na prestação pública de serviços de saúde. As pressões para a reforma, portanto, muitas vezes emanam dos ministérios centrais como os da fazenda e do planejamento. Em muitos casos, os ministérios da saúde esforçam-se para reinterpretar e cumprir diretrizes de política fora de seu controle. $\mathrm{Na}$ Colômbia, uma liderança política forte, combinada com a atuação de consultores externos da Universidade de Harvard, alavancaram as reformas que integraram o sistema de saúde a uma rede mais ampla de seguridade social (Bo SSERT et al., 1998), mas houve uma evidente ausência de "demanda" por parte dos beneficiários.

Recessão e crises fiscais afetam não somente os tipos de políticas públicas que são implementadas, mas também a reação a elas por parte dos usuários, beneficiários 
e cidadãos. A etapa de captação de recursos, por meio da adoção de taxas incidentes sobre o uso de serviços de saúde, para suplementar os recursos orçamentários foi essencial para muitos governos em razão da crise econômica endêmica. Mas o sucesso dessa política, não importa o quão lógica na teoria, foi limitado pela diminuição da capacidade de os cidadãos pagarem pela atenção à saúde. Além disso, o custo administrativo de coletar as taxas e monitorar categorias de usuários isentas freqüentemente excede a receita auferida. A reforma inicial, apesar de bem intencionada, não havia considerado os inevitáveis custos de transação.

Reformas do setor público abarcam um repertório de instrumentos de política, a saber: restrições orçamentárias, reduções de pessoal, aumento de tarifas, terceirização e outras formas de privatização. No setor de saúde, o enfoque foi dado a quatro opções principais, nenhuma das quais mutuamente exclusiva, sendo passíveis de ocorrer ao mesmo tempo. São elas:

- 0 estabelecimento de organizações autônomas;

- a introdução de taxas de usuário;

- a terceirização dos serviços; e

- 0 fortalecimento e a regulação do setor privado.

\section{Restrições de capacidade}

Apesar de amplamente apoiada em fóruns internacionais e por especialistas, a implementação das reformas tem sido muito mais limitada. É difícil avaliar 0 potencial real das reformas de NGP no setor de saúde porque elas foram parciais ou apenas implantadas recentemente. É preciso tempo para uma avaliação mais precisa. Entretanto, não raro, e um tanto ironicamente, os países com a agenda mais radical de reforma parecem ser aqueles com menos capacidade de implementála, ou, como Caiden e Wildavsky (1980) comentaram sarcasticamente, há algumas décadas, sobre planejamento e orçamento: quanto menor a capacidade, maior a ambição e vice-versa. Pemiciosamente, a extensão da recessão econômica em tais contextos requer abordagens radicais no anúncio das políticas e, por outro lado, reduz a capacidade de implementar uma agenda tão radical.

O utros tipos de restrição de capacidade foram identificados, mas nenhuma é incomum. As limitações de recursos humanos em termos de número disponível de servidores capacitados e sua motivação para realizar suas tarefas são problemas amplamente conhecidos. A cultura organizacional comumente milita contra a operação efetiva dos novos modos de governo. Nas organizações que favorecem a hierarquia e o comando, em detrimento de iniciativas e do desenvolvimento de equipe, a autonomia concedida formalmente aos entes governamentais pode não ser plenamente exercida. Apesar de a Nova Gestão Pública enfatizar a importância de vincular o desempenho a recompensas, sistemas inf ormais paralelos comprometem muitas vezes os sistemas formais de recompensa. Um exemplo são as promoções baseadas em patronagem e favoritismos do sistema patrimonial tradicional, em vez de avaliações objetivas de desempenho. É comum que sistemas-chave como o de informação gerencial não funcionem efetivamente. Outra barreira significativa é a falta de incentivos aos indivíduos dentro do setor de saúde para planejar ou monitorar seu trabalho em face das informações produzidas, ou seja, não existe um bom sistema defeedbadk para a auto-correção. 
O utro sinal de fragilidade diz respeito à má coordenação entre os diferentes atores (AKukwe, 1999; Cooper, 1997). Os governos têm grande dificuldade para converter suas declarações de política em estratégias concretas de implementação. O correm, assim, problemas na especificação e a posterior viabilização dos detalhes das políticas de descentralização. Não está claro, por exemplo, em que nível de governo residem os direitos e responsabilidades financeiros. D o mesmo modo, não está claro qual organização deve reportar que dados a quem. São problemas simples, mas desastrosos, de coordenação.

Algumas das restrições à capacidade, naturalmente, estão enraizadas no setor público em geral e não apenas no ministério da saúde ou órgãos semelhantes. Isso vale especialmente para a gestão de recursos humanos, mas aplica-se também a outros sistemas. Por exemplo, até recentemente, todas as receitas geradas pelas taxas de uso de serviços de saúde no Zimbábue tinham que ser repassadas ao Ministério das Finanças, o que resultava em pouco incentivo para sua arrecadação (D LodL o, 1995). Tal desincentivo, em parte, assegurou, ao contrário das expectativas da NGP, que tais taxas tivessem impacto zero sobre a qualidade da atenção à saúde.

Por outro lado, os hospitais locais em Jaipur (Índia) foram autorizados a manter as taxas arrecadadas, ao invés de repassálas ao tesouro do Estado (BJöRKMAN; MATHur, 2002). Esses hospitais não apenas têm hoje um histórico melhor de arrecadação, mas também reinvestem 0 excedente em benefícios de longo prazo como equipamentos de melhor qualidade, estoques mais confiáveis de medicamentos e outros suprimentos médicos e até mesmo redução (ou isenção) da taxa para as pessoas mais carentes. 0 exemplo de
Rajasthan demonstra retornos rápidos nos três critérios clássicos para a atenção à saúde, ou seja, qualidade melhor , acesso mais fácil e custo mais baixo.

Um outro fator que influencia a capacidade e que está fora do controle dos ministérios da saúde é o grau limitado de desenvolvimento do setor privado ou de sua consolidação inadequada, que comprometem os esforços do governo para terceirizar os serviços. A decorrência talvez mais importante disso é que o governo tem poucos exemplos locais de práticas gerenciais eficazes nas organizações com as quais possa aprender. Ou seja, há uma reserva limitada de competências gerenciais para serem aproveitadas.

\section{Tipos de reformas}

Entre as perguntas relevantes para se descreverem as reformas do setor de saúde (RSS), incluem-se quais os tipos dereforma sendo aplicados (ou ao menos recomendados) e se estão funcionando em contextos locais ou mesmo nacionais. Ao tentar respondê-las, é preciso ter em mente que generalizações - ou o seu oposto, exemplos particulares limitados - tendem para uma realidade caricata. Não se deve esquecer que o mundo, particularmente o mundo em desenvolvimento, é vasto e diverso. Se você acredita que as RSS estão funcionando, qual é a evidência concreta para essa alegação? Inversamente, se você é cético, chegou a hora de investigá-las mais a fundo.

Não é preciso assumir uma postura crítica para observar que parte do que está sendo proposto como medidas de RSS são medidas de ajuste estrutural disfarçadas. São normalmente complicadas e, na maior parte, impostas "de cima para baixo". Algumas medidas de reforma demandam grandes mudanças politicamente desgastantes, que 
exigiriam forte determinação para colocálas em prática. Nesses casos, começar, muitas vezes, é um problema em si, de tal forma que planos elaborados de implementação tendem a permanecer na prancheta.

0 aspecto mais importante - e que tende a sobrepujar as restrições mencionadas anteriormente - é o fato de que as reformas propostas passaram a significar intervenções "voltadas para o mercado" no setor de saúde. O conceito foi monopolizado por um paradigma de reformas do setor de saúde liderado pelo Banco Mundial, que corresponde, e nele se embebe, no chamado Consenso de Washington. É importante tratar das premissas subjacentes das RSS voltadas para 0 mercado, hoje agressivamente promovidas ao redor do mundo.

Sem detalhar a análise, parte-se do princípio de que a orientação do setor existente de saúde para o mercado, de forma mais decisiva, resulta em ganhos de eficiência. Entretanto, evidências de que os sistemas de saúde orientados para 0 mercado sejam mais eficientes do que os sistemas públicos não são encontradas sequer em países como os EUA, com seu sistema de saúde já altamente voltado para o mercado (MARMOR, 1998). Quase o dobro dos recursos financeiros (cerca de $14 \%$ do PIB) é necessário nos EUA para fornecer o mesmo tipo e qualidade da atenção disponível nos países da Europa O cidental (que gastam somente $7 \%$ ou $8 \%$ de seu PIB), uma comparação que indica a existência de grandes ineficiências no maior dos sistema de saúde orientado para 0 mercado do mundo.

Um dos motivos principais para esse padrão é que permanece sendo lucrativo ofertar cuidados desnecessários; ademais, nos sistemas em que empresas de seguros privados com fins lucrativos desempe- nham papel importante, os custos de transação (administrativos e outros) são muito altos, da ordem de $20 \%$ a $40 \%$. Conseqüentemente, mesmo empregando critérios de eficiência tradicionais, a evidência de muitos países indica que sistemas públicos de saúde podem não apenas voltar seu foco para a eqüidade, mas também ser mais eficientes do que os sistemas de saúde que tenham base no mercado.

D esnecessário dizer que esta observação não implica que todos os sistemas públicos de saúde sejam eficientes. 0 ponto éque sistemas públicos de saúde ineficientes podem tornar-se mais eficientes com 0 aperfeiçoamento das políticas públicas $\mathrm{Ou}$ seja, adotar uma orientação para 0 mercado não é, por definição, a maneira preferível de melhorar a atenção à saúde para a população. Contudo, as reformas que visam fortalecer as políticas públicas nessa área e o seu financiamento público por meio de impostos são vistos gratuitamente como "inviáveis".

Tal visão é reforçada pelo argumento teórico de economistas do mainstream da saúde, para quem o papel do governo é "corrigir as falhas do mercado" encontradas no setor. A premissa subjacente é de que um "mercado perfeito" - portanto sem falhas - forneceria o melhor sistema de saúde. Mas esse modelo idealista implica que a demanda, conforme expressa pelo poder de compra, deve, em última instância, determinar a oferta e a utilização dos serviços de atenção à saúde. É, assim, por definição, impossível para um mercado perf eito fornecer serviços de acordo com a sua demanda, não levando em conta a capacidade de pagamento daqueles que deles necessitam. Somente se os grupos mais necessitados de atenção fossem também aqueles com recursos disponíveis 
para pagar por ela é que as "forças de mercado" seriam um possível regulador do acesso à saúde.

$\mathrm{Na}$ realidade, como é evidente em todos os países, o oposto é verdadeiro. Os grupos menos privilegiados economicamente são os que sofrem maior incidência de doença, tendo, assim, maior necessidade de atenção. Se se admite esta realidade - e o objetivo ainda é fornecer atenção à saúde de acordo com a necessidade - é preciso buscar maneiras de melhorar o sistema público de saúde, de forma que ele seja capaz de atender às necessidades de saúde e nutrição das pessoas com menos capacidade de pagamento. Essa afirmação, naturalmente, não nega um papel para um setor privado paralelo de saúde que vise ao lucro e que siga as forças de mercado, atendendo principalmente aos grupos mais privilegiados. As conseqüências de tal "saída", porém, devem ser equilibradas com 0 interesse público.

É necessário entender que não há nada inerentemente errado com as reformas na área da saúde baseadas no mercado, contanto que:

- busquem maior eficiência e eqüidade;

- não recebam subsídios do govemo; e

- cumpram regulamentos previamente estabelecidos e bem-monitorados.

Infelizmente, esses pré-requisitos são raros em todos os lugares hoje, incluindo países com "economia socialista de mercado", como a China e o Vietnã.

Mudanças estruturais profundas são cruciais para colocar as reformas no setor de saúde numa trilha sustentável, que conduza a resultados que assegurem atenção mínima para todos os cidadãos. No entanto, a verdade é que a atenção hospitalar pública em muitos países tornou-se inacessível aos pobres, devido às altas taxas cobradas. Os custos adicionais escondidos complicam essa situação - "pagamentos por baixo da mesa" aos médicos são apenas um tipo (A vetisyan , 2002; BARU, 1999). Subsidiar tal sistema, em vez de reformá-lo, somente canalizará fundos adicionais aos receptores errados (os não-pobres).

\section{Estratégias da reforma}

As reformas do setor de saúde são usadas como muletas para dar a impressão de que o sistema está sendo mudado, enquanto permanece basicamente no mesmo curso ou até regride. A questão não é se as pessoas devem compartilhar os custos - porque as pessoas acabam sempre pagando - , mas avaliar quem deve pagar mais e quem deve pagar menos ou não pagar nada. Que mecanismos seriam mais eficazes e sustentáveis?

A melhor resposta é uma outra pergunta: por que não se questionarem diretamente os beneficiários? Essa resposta tem a sabedoria - além de tudo o que já foi dito - de aceitar o fato de que:

- respostas localizadas serão (e devem ser) múltiplas e variadas;

- nenhuma resposta atenderá a todas as (ou mesmo várias) situações diferentes;

- o conhecimento técnico pode ser empregado mais efetivamente em diálogo efetivo com os representantes da comunidade do que em diálogo técnico entre os auto-denominados especialistas;

- uma sabedoria abrangente não é necessariamente a marca registrada das comunidades, como freqüentemente e romanticamente sugerido: elas nem sempre sabem o que lhes é melhor, portanto erros serão cometidos; e

- aprender rapidamente com os erros, mantendo um diálogo contínuo entre 
comunidades e profissionais, pode conduzir à sustentabilidade mais rapidamente do que a adoção de esquemas impostos de fora, não importando o quão promissores possam parecer.

Parafraseando Amartya Sen, para entender as escolhas das pessoas, é preciso saber quais as alternativas lhes estão abertas na vida real. Uma abordagem tão focada na comunidade exige uma mudança sem precedentes nas prioridades e no modus operandi. 0 locus do controle tem de passar para os beneficiários, no caso das decisões que as afetam diretamente em seu cotidiano. O feedback dos usuários - potenciais e atuais - é essencial.

Medidas de política de promoção da eqüidade no setor de saúde têm de ser implementadas a partir do nível central. Até que a situação da eqüidade melhore, alguns dos elementos-chave de tais reformas poderiam ser os seguintes (as porcentagens são meramente ilustrativas e mudarão em cada contexto concreto):

- os serviços públicos de atenção à saúde nas áreas rurais têm de ser financiados primeiramente pelos governos (central e local). 0 governo deve cobrir cerca de $70 \%$ a $75 \%$ dos custos totais; pode-se esperar realisticamente que apenas $10 \%$ a $15 \%$ venham de contribuições da comunidade ou esquemas de seguro saúde rurais; $5 \%$ podem vir da cobrança de taxas diretas e uns $10 \%$, de ajuda internacional;

- os serviços públicos de saúde nas áreas urbanas necessitam de 50\% a 60\% de financiamento do governo; 0 seguro saúde poderia cobrir ao redor de $30 \%$ dos custos e as taxas, $15 \%$; 0 resto poderia vir de ajuda internacional;

- o financiamento da saúde deve afastar-se dos esquemas regressivos de taxa por serviço e aproximar-se dos esquemas de pré-pagamento, para 0 qual a população inteira - não somente os doentes contribui;

- os impostos progressivos diretos e indiretos constituem a base financeira para um sistema eficiente de atenção à saúde voltado para a eqüidade. 0 s fundos do governo podem, então, ser usados para financiar serviços de saúde pública ou subsidiar os esquemas de seguro social de saúde, que, gradualmente, cobrirão a população inteira;

- os governos terão de realocar gradualmente os recursos de estados e municípios mais ricos para os mais pobres, de acordo com um conjunto de índices elaborados com base na necessidade, e, então, a partir deles corrigir os orçamentos recorrentes e de desenvolvimento;

- as receitas tributárias gerais que se aplicam mais aos ricos (impostos sobre artigos de luxo, bebidas alcoólicas, tabaco, patrimônio, imóv eis e renda) são umafonte para se obterem recursos financeiros para o setor de saúde;

- 0 uso dos recursos existentes (sejam humanos, materiais, organizacionais e financeiros) deve ser racionalizado para adaptá-los melhor às necessidades reais. Esta política envolverá a realocação (ou mesmo redução) de pessoal, bem como a mobilização de mais recursos para 0 trabalho de campo fora das unidades de saúde (OMS, 2001). Tudo isso deve ser articulado com reformas de médio prazo que atualizem a renda dos profissionais de saúde, baseada em um sistema de incentivos monetários e não-monetários, a fim de garantir-lhes um padrão mínimo de vida.

Essas são apenas algumas das opções nos níveis central elocal, que merecem uma análise cuidadosa. Mais importante, 0 processo deve abrir as portas para um 
ambiente mais participativo e para 0 fortalecimento do diálogo (especialmente envolvendo as mulheres), a fim de gerar mais opções e respostas. Para que isso aconteça, o processo tem de ser decisivamente direcionado para pontos de partida e chegada concretos, tarefa que os profissionais de saúde podem facilitar.

As reformas do setor público de atenção à saúde não precisam tender totalmente para o setor privado. A propalada idéia de que o serviço público busca o "não-serviço" não é necessariamente verdadeira. Apesar de 0 sistema público conter muitas falhas, tem também muitos pontos fortes. À medida que seu núcleo for enxugado e fortalecido, os serviços subordinados podem ser contratados do setor privado, contanto que haja um sistemajusto de concorrência. $O$ núcleo de um sistema de prestação de serviços deve assegurar a eqüidade como a mais alta prioridade.

Isso nos traz de volta à velha questão da "vontade política", que não é realmente uma questão de "vontade", mas de "escolha" política e compromisso subseqüente. E, sendo uma questão de escolha, apesar do surgimento gradual de iniciativas e movimentos da sociedade civil ao redor do mundo, por ora a responsabilidade de avançar na direção de RSS apropriadas ainda recai sobre os respectivos governos.

\section{Próximos passos}

Na prática, diversas políticas sociais têm sido elaboradas e implementadas como prioridades residuais de políticas econômicas e sido explicitamente rotuladas como programas "compensatórios" para "suavizar" o custo social de ajustes econômicos. Em contrapartida, uma estratégia para reforma social, como discutido anteriormente, exigiria o desenvolvimento de uma ação integrada e coordenada abrangendo os seguintes componentes:

- políticas de reforma econômica, incluindo políticas de estabilização macroeconômica e de ajuste estrutural, que redistribuam ativos produtivos (ex.: eliminação das barreiras de acesso ao crédito, reforma agrária, etc.);

- políticas de reforma dos sistemas de proteção social, incluindo redes de segurança (a proteção de grupos vulneráveis em curto prazo) e programas de seguridade social; e (para complementar efacilitar os itens anteriormente)

- reformas institucionais e administrativas com o objetivo de melhorar a governança de ações públicas por meio do aperfeiçoamento dos processos de tomada de decisão.

As implicações dessas observações em abordagens capacitadoras, especificamente no setor de saúde, não foram completamente exploradas, mas vale a pena enumerar algumas das lições já aprendidas no processo de reforma institucional:

1) as reformas na saúde precisam ser elaboradas e escalonadas de forma realista, refletindo as capacidades existentes. Ao invés de se tentar fazer muito de uma só vez, é mais proveitoso identificar pontos de entrada fáceis sobre os quais as reformas possam-se alicerçar;

2) alguns aspectos da capacidade geralmente aqueles referentes à organização que os implementa - são mais fáceis de serem tratados do que outros. Esforços para a capacitação (ou para a eliminação de barreiras à capacitação) devem começar pelos objetivos menos difíceis de serem alcançados; 
3) muitas das habilidades necessárias para a operação eficiente dos novos modos de governo não podem ser facilmente ensinadas em treinamentos formais, por serem baseadas na experiência. Estratégias de reforma devem ser projetadas para estimular 0 aprendizado pela experiência, especialmente por meio de tutorias e/ ou estágio;

4) unidades de elite e organizações autônomas são geralmente consideradas como atalhos por governos. Embora essa estratégia possa ser um mecanismo eficiente para alcançar metas de alta prioridade em curto prazo, como a expansão de um programa de controle de AID S, por exemplo, seus efeitos em longo prazo são perniciosos. Em outras palavras, a dependência de unidades de elite e organizações autônomas pode impedir que problemas fundamentais sejam tratados: em termos militares, as batalhas são ganhas, mas a guerra é perdida;

5) as comunidades podem ser uma importante fonte de apoio ao governo para o fortalecimento de reformas. Elas também auxiliam a policiar a eficiência do governo, especialmente em países com sociedade civil forte. Tais abordagens, entretanto, devem ser seletivas, para não sobrecarregarem o "terceiro" setor. É importante entender as capacidades e limitações do setor voluntário, não governamental, baseado em comunidades;

6) finalmente, a melhor divulgação das reformas para um público variado profissionais de saúde, políticos e outros - é fundamental, não apenas para a viabilidade política das reformas para gerar apoio, mas também para que esses grupos venham a ter uma participação plena no sistema reformado.

Nenhuma dessas seis estratégias é uma solução à prova de falhas para o problema da reforma do setor de saúde e para a prestação de serviços de qualidade à população apropriada, a um custo razoável. Mas todos têm o seu mérito empírico. A capacitação será, inevitavelmente, desenvolvida em longo prazo, com um cronograma medido em décadas e não em meses ou anos, e as políticas devem ser planejadas de acordo. Elas devem começar a lidar com capacitações básicas de

governo, aquelas que sejam comuns aos sistemas reformados e não reformados.

\section{Governança e desenvolvimento social}

Qual, então, é o papel da governança no desenvolvimento social eem suas políticas? D e acordo com Lavis e Sullivan (1999, p. 312), "Primordialmente, os sistemas de 
saúde desempenham um papel fundamental no porquê de restabelecermos a saúde quando estamos doentes; os ambientes sociais, por sua vez, no porquê, antes de tudo, de sermos saudáveis ou de ficarmos doentes". 0 elo entre desenvolvimento e políticas de saúde requer governança nos dois níveis.

Portanto, a governança na saúde deve viabilizar intervenções médicas para enfrentar desafios como a tuberculose, a malária e a HIV/ AIDS, além de também tratar da questão da transformação social. Na era de globalização, "os determinantes básicos sociais, econômicos e ambientais de saúde para a população estão-se tomando cada vez mais supranacionais" (McMichaEL; Beaglehole, 2000). Para alcançar eficiência nessa era, a governança deve promover tanto as intervenções médicas quanto a transformação social, simultaneamente.

Em 1981, a Assembléia Mundial da Saúde da Organização Mundial da Saúde, endossou a iniciativa "Saúde para todos até 0 ano 2000", para converter a D eclaração de Alma Ata, de 1978, em uma realidade política. A declaração inicial contemplava a saúde como direito humano fundamental, a ser garantido por um processo participativo e abrangente de atendimento básico à saúde, em contexto de desenvolvimento multi-setorial. Antes mesmo de Alma Ata, a saúde surgira como direito humano fundamental na Declaração dos Direitos Econômicos, Sociais e Culturais da ONU. As duas dedarações reconhecem a responsabilidade central do Estado e da comunidade internacional na garantia do direito humano à saúde. Contudo, Alma Ata também enfatizou a importância da comunidade e do lar para a saúde sustentável.

Dada a situação atual da saúde no mundo, fica claro que o "Saúde para todos" não foi concretizado no segundo milênio. Além disso, em nível internacional, as metas de saúde foram revisadas e estão atualmente definidas de forma muito mais estreita, direcionadas a doenças e a metas quantitativas específicas, ao invés de envolverem os aspectos de direito humano universal e de transformação socioeconômica. Embora a meta prevista na declaração de Alma Ata exigisse que a saúde fosse tratada como bem público, a ortodoxia do desenvolvimento neoliberal dos anos 1980 e do início dos 90 interpretoua como bem privado, estratégia de desenvolvimento que afetou a saúde direta e indiretamente. $\mathrm{O}$ papel do mercado na determinação do direito à saúde aumentou, enquanto o papel do Estado diminuiu (D rache; Sullivan, 1999).

D urante os anos 90 , tornou-se cada vez mais evidente que o processo da globalização econômica era acompanhado por uma distribuição desigual de benefícios econômicos. Essa percepção gerou uma alteração na política geral de desenvolvimento global, com o intuito de aliviar seus piores efeitos. Houve grande ênfase na redução da pobreza por meio de mecanismos como as redes de segurança, o microcrédito, as parcerias público-privadas e o perdão de dívidas com a iniciativa em favor dos Países Pobres Altamente Endividados. A noção de "boa governança" também entrou na moda e instituições multilaterais empenharam-se cada vez mais para envolver a sociedade civil no desenvolvimento e na implementação de políticas. A O rganização Mundial da Saúde perdeu espaço para o Banco Mundial, que se tornou a principal fonte de financiamento para 0 setor de saúde e determinou a principal agenda multilateral nessa área (BuSE; G win, 1998; A BBASI, 1999). 
A mudança da estratégia geral de desenvolvimento, baseada no Consenso de Washington, e das relações entre instituições multilaterais chave refletiram-se nas políticas de saúde. O s círculos oficiais de políticas perceberam que um melhor equilíbrio deveria ser estabelecido entre as metas de crescimento econômico e as metas sociais e ambientais, incluindo a saúde. Em 1993, o Banco Mundial publicou o relatório Investindo na saúde, que reiterava a importância do crescimento com eqüidade. Embora a ênfase subseqüente tenha sido dada no envolvimento de um vasto leque de partes interessadas por meio de parcerias público-privadas, essas "parcerias" provaram ser raramente baseadas na igualdade, e aqueles cujos interesses eram declaradamente defendidos eram, na verdade, geralmente excluídos das negociações. Para que as parceiras sejam eficientes, os parceiros da saúde precisam elaborar políticas conjuntamente, bem como unificar seus orçamentos (Sто тт, 1999, p. 822).

A abordagem neoliberal argumentava que eram necessárias novas formas de financiar o saneamento dos problemas da saúde devido ao fracasso dos Estados. A idéia de fracasso dos Estados - ou, pelo menos, de sua ineficiência - estava implícita no relatório do Banco Mundial de 1993. O mercado, porém, também falhou, considerando que o acesso a medicamentos e a serviços de saúde foi restrito à capacidade de comprá-los: muitos (ou até mesmo a maioria), em todo o mundo, não têm recursos suficientes, por isso não têm acesso à saúde. Ao mesmo tempo, devido ao consenso dominante da política de buscar minimizar o papel do Estado, o conceito de provisão pública (nacional ou global) tornou-se uma alternativa antiquada.
A partir de 1990, a apresentação da relação entre saúde precária e pobreza também mudou. Na formulação padrão, saúde precária contribui para a pobreza, porque, quando as pessoas estão doentes, elas são menos produtivas e, assim, tornam-se mais pobres; sendo mais pobres, sofrem mais de saúde precária. A formulação dessa relação, que apresentava a saúde precária como resultado da pobreza, prevalecendo as estruturas socioeconômicas e o modelo dominante de desenvolvimento, passou a apontar a saúde como oportunidade para a redução da pobreza e o desenvolvimento, ou seja, enquanto a pobreza antes era retratada como a causa primária da saúde precária, a ênfase deslocou-se de forma tal que a saúde precária é apresentada agora como causa-chave da pobreza.

Existe uma série de evidências provando que fatores socioeconômicos influenciam a saúde e o bem-estar mais do que intervenções médicas (BJöRKMAN; 2005). D e fato, tem sido sugerido que "0 fator mais importante que influencia a saúde é o tamanho da lacuna entre os ricos e os pobres" (BEZRUCHKA, 2000, p. 322). Beaglehole e Bonita (1998, p. 590) argumentam que "as principais variações nas condições de saúde entre os países resultam de fatores ambientais, socioeconômicos e culturais; o tratamento à saúde é de importância secundária. A pobreza é a mais importante causa de morte, doença e invalidez evitáveis, apesar de apenas um pequeno nível de renda per capita ser necessário para que se alcance uma expectativa de vida aceitável em nível nacional. Alfabetização, acesso à moradia, água limpa, saneamento, alimentação e urbanização também são fortes determinantes na relação entre saúde e pobreza". 


\section{Conclusão}

O Relatório do Banco Mundial de 1993 reconheceu que "políticas governamentais que promovem igualmente a eqüidade e 0 crescimento são melhores para a saúde do que aquelas que promovem apenas 0 crescimento" (BANCo Mundial, 1993, p. 7). Ademais, a boa saúde da população contribui demaneira significativa para posterior crescimento econômico. Intervenções médicas são definitivamentenecessárias para lidar com os problemas de doenças contagiosas eos estados agudos de saúdeprecária, mas uma maior eqüidade socioeconômica é vital para enfrentar o desafio da saúde.

0 direito humano à saúde exige compromisso político em todos os níveis, para a eliminação de desigualdades globais, nacionais e locais, incluindo acesso desigual a serviços de saúde e a tratamento médico. Sem ele, as condições socioeconômicas que tornam o programa "Saúde para todos" realizável não podem existir, nem é possível que passem a existir. São necessárias ações muito além das políticas de saúde, pois as desigualdades na saúde estão enraizadas em estruturas socioeconômicas, e é importante analisar e compreender 0 papel dos diferentes atores que influenciam a saúde da população. A elaboração de um arcabouço conceitual claro das políticas sociais é de particular relevância para a promoção da saúde de maneira eficiente. Tal arcabouço deve ser ajustável a mudanças de idéias, a pesquisas ou a intervenções propostas e deve ser assegurado por compromisso político.

$\mathrm{Na}$ busca de desenvolvimento justo, paradigmas sociais modernos denotam novas perspectivas ecológicas na prevenção de doenças e na proteção, na melhoria e na promoção da saúde em todo o planeta. Elas auxiliam na formulação de políticas viáveis, por meio do aperfeiçoamento e da integração de estratégias internacionais, como as iniciativas "Saúde para todos", "Tratamento básico de saúde" e o planejamento populacional aos planos de saúde nacionais. Paradigmas resolvem conflitos e debates entre os atores envolvidos no processo de políticas sociais em diferentes níveis: por meio deles, formuladores de políticas e profissionais, grupos e indivíduos entendem as causas fundamentais dos problemas do setor de saúde e identificam soluções. 0 conhecimento sobre governança, a consciência dela, a capacidade e os paradigmas modernos podem ajudar a garantir o desenvolvimento social.

(Artigo recebido em julho de 2005. Versão final em setembro de 2005) 


\section{Nota}

* Texto baseado em palestra proferida no curso da ENAP/ENSP/ MDS sobre "Avaliação de programas sociais", em 8 de julho de 2005.

\section{Referências bibliográficas}

Авва SI, I. The World Bank and world health: changing sides. British M edical Journal, 318, p. 865-869, 1999.

AKukwe, Chinua. The need for a closer working relationship between public health and public administration professionals. PA Times, v. 22 n. 4, p. 3-4, 1999.

Avetisyan, N. Provision of health care for the most vulnerable groups in A rmenia: implementation in the government and Armenian Red Cross Society. 2002. Dissertação (Mestrado) Institute of Social Studies, Haia, Países Baixos (não publicada).

Barro s, A. J. D .; C. G. Victora, J. A.; Cesar, J. A.; Neumann, N. A; Bertoldi, A. D. Brazil: are health and nutrition programs reaching the neediest? Washington, D C: Banco Mundial, 2005 (HNP D iscussion Paper n 9).

BARU, R. Private health care in India: social characteristics and trends. Nova D elhi: Sage Publications, 1999.

Beaglehole, R.; Bonita, R. Public health at the crossroads: which ways forward? The L ancet, 351, p. 590-592, 1998.

BezRUCHKA, S. Is globalization dangerous to our health? W estern Journal of M edicine, 172, p. 332-334, 2000.

BJÖ RK MAN, J. W. Health, development and governance. In: HUQUE, A.S.; Zafarullah, H. (ed.). H andbook of inter-national development governance. New York: Auerbach Publications, Taylor \& Francis Group, p. 777-802, 2005 (no prelo).

. Multiple systems, multiple reforms: South Asian health policies in comparative perspective. In: NAGEL, S. (ed.). H andbook of G lobal Technology. New York: Marcel D ekker Inc., p. 167-220, 2001.

Björkman, J. W.; Mathur, K. Policy, technocracy and development: Human Capital Policies in the Netherlands and India. D elhi: Manohar Publishers, 2002.

Bossert, T.; Hsiao, W.; Barrera, M.; Alarcon, L; Leo, M.; Casares, M; Casares, C. Transformation of Ministries of Health in the era of health reform: the case of Colombia. H ealth Policy and Planning 13, p. 59-77, 1998.

Buse, K.; G win, C. World health: the World Bank and global cooperation in health: The Case of Bangladesh. The L anœt 351, p. 665-669, 1998. 
Caiden, N.; Wildavsky, A. Planning and budgeting in poor countries. New Brunswick, New Jersey: Transaction Books, 1980.

Cooper, G.A. H ealth sector reform: a study of contracting of local government primary health care delivery to NG O s in Mumbai (India). 1997. D issertação. (Mestrado) - Institute of Social Studies, Haia, Países Baixos (não publicada).

DLOdL 0, F. The impact of user-fee policy on national utilization of health serviœs: case studies in Zimbabwe. 1995. Dissertação. (Mestrado) - Institute of Social Studies, Haia, Países Baixos (não publicada).

Drache, D.; Sullivan , T. (Ed.) M ark et limits in health reform: public success, private failure. Londres: Rutledge, 1999.

Esman, M.J. Management dimensions of development: perspectives and strategies. West Hartford, Connecticut: Kumarian Press, Inc, 1999.

HinRICHS, K. Health care policy in the German social insurance state: from solidarity to privatization?. Policy Studies Review 19, p. 108-140, 2002.

Hood, C. A public management for all seasons?. Public A dministration 69, p. 3-19, 1991. Lavis, T.; Sullivan, T. G overning health. In: Drache, D.; T. Sullivan. (Ed.) mark et limits in health reform: public success, private failure. Londres: Rutledge, p. 312-328, 1999.

MARMOR, T.R.Hope e hyperbole: the rhetoric and reality of managerial reform in health care. Journal of $\mathrm{H}$ ealth Serviœs Research and Policy 3, p. 62-4, 1998.

Mcmichael, A.; Beaglehole R. The changing global context of public health. The L anœet 356, p. 495-499, 2000.

NARAY ANA, D . public expenditure reform without policy change: infrastructure investment and health care provision under fiscal squeeze in Kerala. In: Mackinto sh, M.; Roy, R. (Ed.) E conomic D ecentralization and Public M anagement R eform. Cheltenham: Edward Elgar, p. 106-121, 1999.

Nelson, J. The politics of social sector reforms. Washington DC: Overseas Development Council, 2000.

PALMER, N. The use of private sector contracts for primary health care: theory, evidence and lessons for low income and middle income countries. Bulletin of the World $\mathrm{H}$ ealth O rganization 78, p. 821-829, 2000.

Sтотт, R. The World Bank: friend or foe? British M edical Journal 318, p. 822-823, 1999.

UND P. H uman D erelopment Report 2003: Millennium Development Goals - A compact among nations to end human poverty. New York: UNDP, 2003. Disponível em <www.undp.org/ hdr2003/ pdf/ hdr03_cojmplete.pdf >.

Viana, A.; QueIroz, M.; IBAÑEz, N. Implementation of a single health system: new relationships between the public and private sectors in Brazil. In: Altenstetter, C.; BJö RKman, J.W. (Ed.) H ealth Policy Reform, N ational V ariations and G lobalization. Londres: Macmillan Press Ltd., p. 331-347, 1997.

WANG , Y. Health systems decentralization and human resources management in low and middle income countries. Public A dministration and D evelopment 22, p. 449-454, 2002. 
Whyte, A. L andscape analysis of donor trends in international development. New York: The Rockefeller Foundation, 2004.

WorLD BANK. W orld D evelopment Report 1993: investing in health. Washington D C: World Bank, 1993.

W orld D evelopment Report 1997: changing role of the State. New York: Oxford University Press, 1997. . India - Raising the sights: better health systems for India's poor. Washington D C: World Bank, 2001. (Report no 22304, HNP Sector India)

World Health Organization. M acroeconomics and health: investing in health for economic development. Genebra: O rganização Mundial da Saúde, 2001. 


\section{Resumo - Resumen - Abstract}

\section{Política social, govemança e capacidade: reformas e restrições do setor público}

James Warner Björk man

Tendo como pano de fundo a natureza problemática das tentativas de ref ormar os sistemas nacionais de prestação de serviços sociais e de saúde, esteartigo busca fazer uma revisão da lógica da Nova G estão Pública (NGP) no setor de serviços de saúde. A pós contextualizar as diver sas abordagens da capacitação em políticas sociais e as três gerações de reformas do setor público, faz um exame das reformas aplicadas na prestação de serviços de saúde, sugerindo estratégias que levem em conta a capacidade. $O$ artigo finaliza com uma discussão so bre o papel da governançana política social eno desenvolvimento.

Palavras-chave: atenção à saúde, reforma do setor público, capacitação

\section{Política social, govemanza y capacidad: reformas y restricciones del sector público}

James Warner Björk man

Teniendo en cuenta la naturaleza problemática de las tentativas de reformar los sistemas nacionales de entrega de servicios sociales y de salud, en este artículo se hace una revisión de la lógica de la Nueva G estión Pública (NGP) en el sector de servicios de salud. D espués de contextualizar los diversos abordajes de capacitación en políticas sociales y las tres generaciones de reformas del sector público, propone un examen de las reformas aplicadas en la entrega de servicios de salud y sugiere estrategias que tomen en consideración la capacidad. El artículo finaliza con una discusión sobre el rol de la governanza en la política social y en el desarrollo.

Palabras-clave: atención de la salud, reforma del sector público, capacitación

\section{Social policy, governance and capacity: public sector reforms and restraints} James Warner Björk man

Given the problematic nature of attempts to reform national delivery systems for social and health care, the essay reviews the logic of New Public Management (NPM) in the health service sector. Aftera background on approaches to building capacity for social policy and the three generations of public sector reforms, it examines the reforms applied to the delivery of health services and suggests strategies for reforming the health sector that take capacity into account. It concludes with a discussion of the role of governance in social policy and development.

Key words: health care, public sector reform, capacity building

James Warner Björkman

Professor do Instituto de Estudos Sociais (Haia) e do Rijksuniversiteit Leiden (Países Baixos). Contato: <bjorkman@iss.nl> 